\title{
Papers
}

\section{Prevalence of Gulf war veterans who believe they have Gulf war syndrome: questionnaire study}

\author{
T Chalder, M Hotopf, C Unwin, L Hull, K Ismail, A David, S Wessely
}

\begin{abstract}
Objectives To determine how many veterans in a random sample of British veterans who served in the Gulf war believe they have "Gulf war syndrome," to examine factors associated with the presence of this belief, and to compare the health status of those who believe they have Gulf war syndrome with those who do not.

Design Questionnaire study asking British Gulf war veterans whether they believe they have Gulf war syndrome and about symptoms, fatigue, psychological distress, post-traumatic stress, physical functioning, and their perception of health.

Participants 2961 respondents to questionnaires sent out to a random sample of 4250 Gulf war veterans $(69.7 \%)$.

Main outcome measure The proportion of veterans who believe they have Gulf war syndrome.

Results Overall, 17.3\% (95\% confidence interval 15.9 to 18.7) of the respondents believed they had Gulf war syndrome. The belief was associated with the veteran having poor health, not serving in the army when responding to the questionnaire, and having received a high number of vaccinations before deployment to the Gulf. The strongest association was knowing another person who also thought they had Gulf war syndrome.

Conclusions Substantial numbers of British Gulf war veterans believe they have Gulf war syndrome, which is associated with psychological distress, a high number of symptoms, and some reduction in activity levels. A combination of biological, psychological, and sociological factors are associated with the belief, and these factors should be addressed in clinical practice.
\end{abstract}

\section{Introduction}

The term "Gulf war syndrome" has been used to describe a variety of symptoms and illnesses experienced by veterans of the 1991 Gulf war. There is no consensus as to how to define Gulf war syndrome, and attempts to specify and measure the syndrome have led to contradictory findings and interpretations. ${ }^{1-3}$ In previous papers, we found that, although veterans deployed to the Gulf reported more symptoms than veterans deployed to Bosnia and those who were not deployed, ${ }^{4}$ the constellations of symptoms in all three groups were similar. ${ }^{3}$ We suggested that vaccination against biological warfare agents contributed to this ill health, but we also found that all military exposures were associated with all outcomes. ${ }^{45}$ Several groups have confirmed that two to three times more Gulf war veterans report symptoms than appropriate controls, but conclude that there is no unique Gulf war syndrome. $^{24} 67$

Some veterans believe that they have a condition called Gulf war syndrome and attribute their symptoms to this. We are not aware of any systematic studies investigating the views of veterans or estimating the prevalence of such a belief. This information is important as the beliefs and views of the veterans may determine symptom reporting, health perception, degree of associated disability, and help-seeking behaviour. For example, a belief that the syndrome is caused by vaccinations may hamper efforts to ensure that servicemen and servicewomen are protected against threats such as chemical and biological weapons.

The purpose of this paper was to determine how many veterans deployed to the Gulf believed they have Gulf war syndrome, to compare health outcomes between those who believed they have Gulf war syndrome and those who did not, and to examine factors associated with the belief.

\section{Methods}

Ethical approval was gained for the study. In August and September 1997, questionnaires were sent to a randomly chosen, large sample $(n=4250)$ of British servicemen and servicewomen who served in the Gulf war in 1991. ${ }^{4}$ Two follow up mailings were completed by November 1998. All service personnel were asked questions about their age, sex, marital status, education, occupational factors (rank, current service status, and duties during the Gulf war), cigarette smoking habits, and alcohol consumption and about their experience of 30 military exposures including environmental exposures, such as smoke from fires in oil wells or depleted uranium, and military stressors, such as witnessing maimed or injured bodies or being under fire. In our previous paper, these exposures were universally associated with adverse health outcomes, although we could not detect specific associations. ${ }^{4}$ In this paper, therefore, we present data on exposures in categories according to the total number of recorded exposures. Participants were asked about the number of vaccines they received before and during deploy-
Gulf War Research
Unit, Guy's, King's
College, and St
Thomas's School of
Medicine, King's
College, London
SE5 8AZ
T Chalder
reader
M Hotopf
reader
C Unwin
study coordinator
L Hull
research assistant
K Ismail
lecturer
A David
codirector
S Wessely
codirector
Correspondence to:
T Chalder
sphatrc@iop.
kcl.ac.uk
BMJ 2001;323:473-6 
Table 1 Sociodemographic characteristics of Gulf war veterans responding to a questionnaire survey

\begin{tabular}{|c|c|c|c|c|}
\hline & $\begin{array}{c}\text { No of } \\
\text { exposed } \\
\text { veterans }\end{array}$ & $\begin{array}{l}\text { No of exposed } \\
\text { veterans with self } \\
\text { reported "Gulf war } \\
\text { syndrome" (\%) }\end{array}$ & $\begin{array}{c}\text { Odds ratio } \\
(95 \% \mathrm{Cl})\end{array}$ & $\begin{array}{l}\text { Adjusted odds } \\
\text { ratio† }(\mathrm{n}=2470)\end{array}$ \\
\hline \multicolumn{5}{|l|}{ Sex: } \\
\hline Male & 2741 & 474 (17.3) & & \\
\hline Female & 210 & $36(17.1)$ & $1.0(0.7$ to 1.4$)$ & $1.1(0.7$ to 1.8$)$ \\
\hline \multicolumn{5}{|l|}{ Age: } \\
\hline$<30$ & 807 & $148(18.3)$ & 1.0 & 1.0 \\
\hline $30-34$ & 908 & $159(17.5)$ & $0.9(0.7$ to 1.2$)$ & $1.0(0.8$ to 1.4$)$ \\
\hline $35-40$ & 597 & $87(14.6)$ & $0.8(0.6$ to 1.0$)$ & $0.8(0.6$ to 1.2$)$ \\
\hline$>40$ & 641 & $117(18.3)$ & $1.0(0.8$ to 1.3$)$ & $1.1(0.7$ to 1.5$)$ \\
\hline \multicolumn{5}{|l|}{ Level of education achieved: } \\
\hline Below 0 level or GCSE & 517 & $132(25.5)$ & $3.7(2.2$ to 6.0$)$ & $3.0(1.5$ to 6.0$)$ \\
\hline 0 level or GCSE & 1722 & $289(16.8)$ & 2.2 (1.3 to 3.5$)$ & 2.0 (1.0 to 3.8$)$ \\
\hline A level & 404 & $51(12.6)$ & $1.5(0.9$ to 2.7$)$ & $1.6(0.8$ to 3.1$)$ \\
\hline Degree & 234 & $20(8.6)$ & 1.0 & 1.0 \\
\hline \multicolumn{5}{|l|}{ Currently serving: } \\
\hline Yes & 1746 & $200(11.5)$ & & \\
\hline No & 1163 & $302(26.0)$ & 2.7 (2.2 to 3.3$)$ & $2.6(2.1$ to 3.2$)$ \\
\hline \multicolumn{5}{|l|}{ Rank: } \\
\hline Officer & 398 & $31(7.8)$ & & \\
\hline Other ranks & 2560 & $481(18.8)$ & 2.7 (1.9 to 4.0$)$ & $1.7(1.0$ to 3.9$)$ \\
\hline \multicolumn{5}{|l|}{ Ethnic group: } \\
\hline White & 2919 & $502(17.2)$ & & \\
\hline Non-white & 34 & $8(23.5)$ & $1.5(0.7$ to 3.3$)$ & $1.2(0.5$ to 3.2$)$ \\
\hline \multicolumn{5}{|l|}{ Duties in Gulf war: } \\
\hline Logistical & 734 & $123(16.8)$ & 1.0 & 1.0 \\
\hline Combative & 575 & $130(22.6)$ & $1.5(1.1$ to 1.9$)$ & 1.4 (1.1 to 1.9$)$ \\
\hline Signalling & 199 & $30(15.1)$ & $0.9(0.6$ to 1.4$)$ & $1.0(0.6$ to 1.6$)$ \\
\hline Medical & 340 & $66(19.4)$ & $1.2(0.9$ to 1.7$)$ & $1.3(0.9$ to 1.9$)$ \\
\hline Staff & 101 & $7(6.9)$ & $0.4(0.2$ to 0.8$)$ & $0.6(0.2$ to 1.3$)$ \\
\hline Other & 658 & $79(12.0)$ & $0.7(0.5$ to 0.9$)$ & $0.7(0.5$ to 1.0$)$ \\
\hline \multicolumn{5}{|l|}{ Marital status: } \\
\hline Married & 2228 & $370(16.6)$ & 1.0 & 1.0 \\
\hline Never married & 459 & $85(18.5)$ & $1.1(0.9$ to 1.5$)$ & $0.9(0.7$ to 1.3$)$ \\
\hline Previously married & 254 & $52(20.5)$ & $1.3(0.9$ to 1.8$)$ & $1.0(0.7$ to 1.5$)$ \\
\hline
\end{tabular}

Data are missing for some respondents.

${ }^{\star}$ Exposed to 30 military exposures including experiencing environmental exposures, such as smoke from fires in oil wells or depleted uranium, and military stressors, such as witnessing maimed or injured bodies or being under fire.

†Adjusted for age, sex, education, marital status, ethnic group, duty in gulf, and rank.

Table 2 Relation between self reported Gulf war syndrome and other health outcomes

\begin{tabular}{|c|c|c|c|c|}
\hline & \multirow[b]{2}{*}{$\begin{array}{l}\text { No with each } \\
\text { outcome }\end{array}$} & \multirow{2}{*}{$\begin{array}{l}\text { No }(\%) \text { with each health } \\
\text { outcome also with self } \\
\text { reported Gulf war } \\
\text { syndrome }\end{array}$} & \multicolumn{2}{|c|}{ Odds ratio $(95 \% \mathrm{CI})$} \\
\hline & & & Unadjusted & Adjusted* \\
\hline \multicolumn{5}{|c|}{ Case according to general health questionnaire ${ }^{6}$} \\
\hline No & 1857 & $134(7.2)$ & & \\
\hline Yes & 1050 & $365(34.8)$ & $6.9(5.4$ to 8.6$)$ & $5.9(4.6$ to 7.5$)$ \\
\hline \multicolumn{5}{|c|}{ Case according to Centers for Disease Control and Prevention criteria ${ }^{2}$} \\
\hline No & 1212 & $48(4.0)$ & & \\
\hline Yes & 1737 & $462(26.6)$ & $8.6(6.3$ to 11.8$)$ & $9.0(6.3$ to 13.0$)$ \\
\hline \multicolumn{5}{|c|}{ Case according to fatigue questionnaire ${ }^{7}$} \\
\hline No & 1654 & $78(4.7)$ & & \\
\hline Yes & 1222 & $415(34.0)$ & $10.6(8.0$ to 14.0$)$ & $9.9(7.4$ to 13.2$)$ \\
\hline \multicolumn{5}{|c|}{ Post-traumatic stress reaction } \\
\hline No & 2600 & $304(11.7)$ & & \\
\hline Yes & 352 & $206(58.5)$ & 10.6 (8.1 to 13.8$)$ & 7.3 (5.5 to 9.8 ) \\
\hline
\end{tabular}

Data are missing for some respondents.

*Adjusted for rank, duties, level of education achieved, and whether serving in the military at the time of the questionnaire.
Health outcomes were assessed using the general health questionnaire (a measure of psychological distress) ${ }^{8}$ the fatigue questionnaire, ${ }^{9}$ the health perception and physical functioning subscales of the SF-36 health survey, ${ }^{10}$ and a list of symptoms based on the Hopkins symptom checklist ${ }^{11}$ tailored to the experience of Gulf war service personnel. A measure of posttraumatic stress reaction, a proxy for post-traumatic stress and the multisymptom illness as classified by Centers for Disease Control and Prevention, ${ }^{2}$ was created from items in the symptom checklist.

Data were analysed in Stata 6 (StataCorp, College Station, TX). Logistic regression was used to examine univariate and multivariate associations between demographic variables, health outcomes, other specific risk factors, and the main explanatory variable (dependent variable)-belief in having Gulf war syndrome. Multiple regression was used to examine differences in health perception, physical functioning, and physical symptoms between veterans who did and did not believe they had Gulf war syndrome.

\section{Results}

Response rates and differences between responders and non-responders have been reported. ${ }^{4}$ After three mailings, the response rate was 2961/4250 (69.7\%). Overall, 513/2961 (17.3\%, 95\% confidence interval $15.9 \%$ to $18.7 \%$ ) participants believed they had Gulf war syndrome; the remaining 2448 (82.7\%) participants did not. Those who believed they had Gulf war syndrome were more likely to be of lower rank, were less likely to be still serving in the army, and were less well educated than those who did not believe they had Gulf war syndrome (table 1). There were more smokers among veterans who believed they had Gulf war syndrome $(n=241 / 513,47 \%)$ than among those who did not $(\mathrm{n}=174,34 \%)$.

Of those who believed they had Gulf war syndrome, $462(90 \%)$ fulfilled Centers for Disease Control and Prevention criteria for the illness. ${ }^{2}$ When disability was also considered, only $221(43 \%)$ of the veterans who believed they had Gulf war syndrome were symptomatic and disabled according to the criteria. Those who believed they had Gulf war syndrome were more fatigued, more distressed, more likely to have a post-traumatic stress reaction, and more likely to fulfil Centers for Disease Control and Prevention criteria for multisymptom illness (table 2). When we adjusted for rank, duty, education, and current service in the military, there was no substantial difference in the pattern of results.

Univariate analyses showed that those who believed they had Gulf war syndrome had worse health perceptions, were more physically disabled, and reported more symptoms than those who did not (table 3).

We examined factors that could potentially be associated with a belief in having Gulf war syndrome, such as number of exposures reported, number of vaccines received, and knowing other people with Gulf war syndrome. We adjusted for confounding factors that had the potential to distort the results-such as education, rank, whether serving in the army at the time of the questionnaire, and health outcomes, including distress, fatigue, physical symptoms, and physical functioning,
Participants were also asked whether they thought they had Gulf war syndrome and whether they knew other people who had Gulf war syndrome. 
Table 3 Differences in health perception and physical functioning measured on the SF-36 health survey, and total physical symptoms. Values are numbers $(95 \%$ confidence interval)

\begin{tabular}{lcccc} 
& Did not believe they had Gulf war syndrome & Believed they had Gulf war syndrome & Adjusted mean difference $^{*}$ \\
\hline Health perception & $73.4(72.6$ to 74.2$)$ & 40.7 (38.3 to 43.0$)$ & $30.5(28.2$ to 32.8$)$ \\
\hline Physical functioning & $94.5(94.0$ to 95.0$)$ & $80.3(79.3$ to 82.3$)$ & $11.6(10.0$ to 13.1$)$ \\
\hline Physical symptoms & $7.9(7.6$ to 8.2$)$ & $20.6(19.7$ to 21.5$)$ & $11.4(10.5$ to 12.2$)$
\end{tabular}

*Adjusted for education, whether serving in the army at the time of the questionnaire, and rank.

that may have influenced individual's beliefs and behaviour. In the unadjusted analysis, more exposures, more vaccines, and knowing someone else with Gulf war syndrome were all associated the with belief. After adjustment, there was no association between the number of exposures and the belief. However, those who had received more vaccinations $(\geqslant 7)$ and knew other people with Gulf war syndrome were more likely to believe they had Gulf war syndrome $(\mathrm{P}<0.05)$. The strongest association was knowing other people with Gulf war syndrome $(\mathrm{P}<0.001)$. The odds increased when confounding factors were controlled for, including health outcomes (table 4). Of the participants, $444(86.5 \%)$ veterans who believed they had Gulf war syndrome attributed a change in functioning to their service in the Gulf. They were not asked about which aspect of their service was related to that change in functioning.

\section{Discussion}

In our sample of British Gulf war veterans $17 \%$ believed they had Gulf war syndrome. If this sample is representative, ${ }^{4}$ about 9000 of 53000 British service personnel believe they have Gulf war syndrome. To the best of our knowledge this study is the first to report the number of British service personnel deployed to the Gulf who, six years after the conflict, believed they have Gulf war syndrome.

The strongest factor associated with the belief was knowing another person who held the same belief. The odds ratio was not affected by distress or disability, states that could have existed prior to, or resulted from, service in the Gulf.

Veterans who believed they had Gulf war syndrome reported worse health outcomes than those who did not. They were more symptomatic, distressed, and fatigued, and they were more likely to have a post-traumatic stress reaction. They were also more physically disabled, and their health perceptions matched their experience in that they perceived themselves to be unhealthy.

Veterans who have symptoms believe that they have Gulf war syndrome because the most likely explanation for the symptoms stems from something they have in common-their active service. It is possible that the $17 \%$ of veterans who believed they had the syndrome had a unique adverse exposure not experienced by the $83 \%$ who do not. The greater the number of vaccinations veterans received, the more likely they were to believe they had Gulf war syndrome. The largest factor associated with the belief was knowing someone else who also believed they had the condition.

Collectively, Gulf war veterans shared in a hazardous situation resulting, for some, in ill health. Concern over one's health may lead a person to seek support from peers in a similar position. As a result, a system of beliefs around the illness in which the veter- ans shared ideas about the nature and cause of their symptoms may have evolved, and this may have had an integrating function on the group. This would fit in with the army's philosophy of encouraging two-man buddy systems, because members of close-knit groups are thought to be more able to cope with adversity. ${ }^{12}$ However, social networks may have played a different role in this case and information about the "illness" transmitted from one person to another increased fear and awareness, resulting in more symptoms, more distress, and increased levels of disability.

At present, 2801 British veterans have attended the medical assessment programme that is organised by the Ministry of Defence and is available to any Gulf war veteran with concerns about their health. ${ }^{13}$ Recent parliamentary answers confirm that the number of veterans concerned about their health is declining, and the future of the programme is in doubt. However, our results are cause for concern and show that, at the time of the survey, many servicemen believed their health had been adversely affected by their service in the Gulf war. Given that the armed forces represent a group of people chosen because of their good health and fitness, this is alarming. It also has implications for the willingness of armed forces personnel to participate in future health protection programmes intended to protect against the threat of chemical and biological warfare.

More optimistically, although those who believe their symptoms are part of the Gulf war syndrome are disabled, they are not as incapacitated as might be expected. This may be related to attitudes to physical fitness in the armed forces, in which exercise is promoted and incorporated routinely into military life.

Table 4 Relation between exposures and self reported Gulf war syndrome. Values are numbers (percentages) unless otherwise specified

\begin{tabular}{|c|c|c|c|c|}
\hline & \multirow[b]{2}{*}{ Total veterans } & \multirow{2}{*}{$\begin{array}{l}\text { Veterans with } \\
\text { self reported } \\
\text { Gulf war } \\
\text { syndrome }\end{array}$} & \multicolumn{2}{|c|}{ Odd ratio $(95 \% \mathrm{CI})$} \\
\hline & & & Unadjusted & Adjusted* \\
\hline \multicolumn{5}{|c|}{ Total exposures reported: } \\
\hline $0-3$ & 316 & $32(10.1)$ & 1.0 & 1.0 \\
\hline $4-7$ & 660 & 87 (13.2) & 1.3 (0.9 to 2.1$)$ & 1.1 (0.6 to 2.2$)$ \\
\hline 8-11 & 890 & $137(15.4)$ & 1.6 (1.1 to 2.4$)$ & $0.9(0.5$ to 1.8$)$ \\
\hline $12-15$ & 761 & $164(21.6)$ & 2.4 (1.6 to 3.7$)$ & $0.9(0.5$ to 1.8$)$ \\
\hline$\geqslant 16$ & 301 & $89(29.6)$ & 3.7 (2.4 to 5.8$)$ & $1.2(0.6$ to 2.4$)$ \\
\hline \multicolumn{5}{|c|}{ Total number of vaccines received: } \\
\hline $0-2$ & 485 & $55(11.3)$ & $1.4(0.0$ to 2.0$)$ & $1.2(0.7$ to 2.0$)$ \\
\hline 3-4 & 503 & $77(15.3)$ & 1.6 (1.1 to 2.5$)$ & $1.6(0.9$ to 2.8$)$ \\
\hline 5 & 291 & $51(17.5)$ & 1.8 (1.3 to 2.7$)$ & 1.7 (1.0 to 2.8$)$ \\
\hline 6 & 407 & 77 (18.9) & 2.8 (1.9 to 3.9$)$ & $1.8(1.1$ to 3.0$)$ \\
\hline$\geqslant 7$ & 485 & $126(26.0)$ & & \\
\hline \multicolumn{5}{|c|}{ Knowing other people with Gulf war syndrome: } \\
\hline Yes & 506 & $179(35.4)$ & $3.5(2.8$ to 4.4$)$ & $3.87(2.7$ to 5.5$)$ \\
\hline
\end{tabular}

Data are missing for some respondents.

${ }^{*}$ Adjusted for level of education attained, whether still in service at the time of the study, and rank plus scores on the general health questionnaire, fatigue scores, physical symptoms, and physical functioning. 


\section{What is already known on this topic}

The term Gulf war syndrome has been used to describe illnesses and symptoms experienced by veterans of the 1991 Gulf war

Concerns exist over the validity of Gulf war syndrome as a unique entity

\section{What this study adds}

$17 \%$ of Gulf war veterans believe they have Gulf war syndrome

Holding the belief is associated with worse health outcomes

Knowing someone else who believes they have Gulf war syndrome and receiving more vaccinations were associated with holding the belief

It may also result from the way in which armies prepare personnel for exposure to adversity, in the hope that they will not become disabled and that the likelihood of subsequent illness is reduced. ${ }^{12}$

The future health needs of the all service personnel should now be considered. As research findings are published, pertinent information should be fed back to all service personnel in order to minimise misconceptions about the nature of the illness and to prevent competing models of illness that may be harmful.

Contributors: TC had the original idea for the study, framed the hypotheses, contributed to the analyses, prepared the manu- script, and acts as guarantor. MH conducted the main analyses. $\mathrm{CU}$ was the study coordinator. $\mathrm{LH}$ assisted with data collection. $\mathrm{KI}$ assisted in the study design and data collection. SW and $\mathrm{AD}$ were the grant holders and contributed to the manuscript.

Funding: United States Department of Defense funded this study. Neither United States Department of Defense nor British Ministry of Defence contributed to the design, analysis, or reporting of the study.

Competing interests: None declared.

1 Haley R, Thomas L, Hom J. Is there a Gulf war syndrome? Searching fo syndromes by factor analysis of symptoms. JAMA 1997;277:215-22.

2 Fukuda K, Nisenbaum R, Stewart G. Chronic multisymptom illness affecting air force veterans of the Gulf war. JAMA 1998;280:981-8.

3 Ismail K, Everitt B, Blatchley N, Hull L, Unwin C, David A, et al. Is there a Gulf war syndrome? Lancet 1999;353:179-82.

4 Unwin C, Blatchley N, Coker W, Ferry S, Hotopf M, Hull L, et al. Health of UK servicemen who served in Persian Gulf War. Lancet 1999;353:16978.

5 Hotopf M, David A, Hull L, Ismail K, Unwin C, Wessely S. The role of vaccinations as risk factors for ill health in veterans of the Gulf war: cross sectional study. BMJ 2000:320:1363-7.

6 The Iowa Persian Gulf Study Group. Self-reported illness and health status among Gulf war veterans. A population-based study. JAMA 1997;277:238-45.

7 Cherry N, Creed F, Silman A, Dunn G, Baxter D, Smedley J, et al. Health and exposures of United Kingdom Gulf war veterans. Part I: the pattern and extent of ill health. Occup Environ Med 2001;58:291-8.

8 Goldberg D, Williams P. A user's guide to the general health questionnaire. Windsor: NFER-Nelson, 1988

9 Chalder T, Berelowitz G, Pawlikowska T, Watts L, Wessely S, Wright D, et al. Development of a fatigue scale. J Psychosom Res 1993;37:147-53.

10 Stewart A, Hays R, Ware J. The MOS short-form general health survey: reliability and validity in a patient population. Med Care 1988:26:724-32.

11 Derogotis L, Lipman R, Rickels K, Uhlenhuth E, Covi L. The Hopkins symptom checklist (HSCL): a self report symptom inventory. Behav Sci 1974;19:1-15.

12 O'Brien LS. Traumatic events and mental health. Cambridge: Cambridge University Press, 1998.

13 Coker W, Bhatt B, Blatchley N, Graham J. Clinical findings for the first 1000 Gulf war veterans in the Ministry of Defence's medical assessment programme. BMJ 1999;318:290-4.

(Accepted 24 May 2001)

\title{
Teenage pregnancy and risk of adverse perinatal outcomes associated with first and second births: population based retrospective cohort study
}

\author{
Gordon C S Smith, Jill P Pell
}

Department of Obstetrics and Gynaecology, Glasgow, Oueen Mother's Hospital, Glasgow G3 8SH

Gordon C S Smith. specialist registrar in maternal-fetal medicine

continued over

BMJ 2001;323:476-9

\section{bmj.com}

The full version of this paper is available on the BMJ's website

\begin{abstract}
Objective To determine whether first and second births among teenagers are associated with increased risk of adverse perinatal outcomes after confounding variables have been taken into account.

Design Population based retrospective cohort study using routine discharge data for 1992-8.

Setting Scotland.
\end{abstract}

Main outcome measures Stillbirth, preterm delivery, emergency caesarean section, and small for gestational age baby among non-smoking mothers aged 15-19 and 20-29.

Results The 110233 eligible deliveries were stratified into first and second births. Among first births, the only significant difference in adverse outcomes by age group was for emergency caesarean section, which was less likely among younger mothers (odds ratio $0.5,95 \%$ confidence interval 0.5 to 0.6 ). Second births in women aged 15-19 were associated with an increased risk of moderate (1.6, 1.2 to 2.1$)$ and extreme prematurity $(2.5,1.5$ to 4.3$)$ and stillbirth (2.6 1.3 to 5.3) but a reduced risk of emergency caesarean section $(0.7,0.5$ to 1.0$)$.

Conclusions First teenage births are not independently associated with an increased risk of adverse pregnancy outcome and are at decreased risk of delivery by emergency caesarean section. However, second teenage births are associated with an almost threefold risk of preterm delivery and stillbirth.

\section{Introduction}

Teenage pregnancy is an important public health problem as it often occurs in the context of poor social support and maternal wellbeing. Some studies have suggested that first teenage pregnancies have a higher frequency of adverse perinatal outcomes. ${ }^{12}$ However, 